\title{
The effect of Psoriasis on Female Sexual Function
}

\author{
Amany Abdelrahman Nassar, Al-shimaa Mohammed Ibrahim, Heba Mohammed Mohammed Salem* \\ Department of Dermatology, Venereology and Andrology, Faculty of Medicine - Zagazig University, Egypt. \\ *Corresponding Author: Heba Mohammed Mohammed Salem, Mobile: (+20)01111134983, \\ Email: mosad8rashed@gmail.com
}

\begin{abstract}
Background: Psoriasis is one of the most common immune-mediated chronic inflammatory skin disorders. Sexual dysfunction in psoriasis is influenced by factors such as the severity of psoriasis, psoriasis body area and associated physical and/ or psychic comorbidities.

Objective: The study aimed to assess female sexual dysfunction and their correlation with psoriasis severity.

Patients and Methods: The present study was conducted on two groups: patient group that included 30 female patients with psoriasis, with age ranged from 20-60 years old and control group included 20 healthy females, with matched age. The disease severity was graded according to the Psoriasis Area and Severity Index (PASI) score. Female sexual function was assessed by female sexual function Index (FSFI).

Results: The mean of all six FSFI domains were lower in psoriatic group than in control group except pain was increased and with no statistically significant difference between both groups. Orgasm was found to be significantly decreased in female patients with psoriasis than control group. There was a significant negative correlation between female sexual function index (FSFI) and psoriasis severity (PASI). There was a significant negative correlation between age and FSFI among control group. In contrast to psoriasis group, there was no correlation between FSFI and either age or duration of disease.
\end{abstract}

Conclusion: There was a significant negative correlation between FSFI and PASI.

Keywords: PASI, FSFI, Female sexual dysfunction.

\section{INTRODUCTION}

Psoriasis is one of the most common immunemediated chronic inflammatory skin disorders ${ }^{(\mathbf{1})}$. Beside genetic factors, several environmental factors such as injuries, infections, stress, drugs, and immune defect take part in autoimmune pathogenesis of the disease. In addition, it has been reported that some hormones may also have a role in the pathogenesis of psoriasis, due to their effects on keratinocytes proliferation ${ }^{(2)}$. Studies revealed that sex hormones manifest a variety of biological and immunological effects in the skin which modulate the natural course of psoriasis ${ }^{(3)}$.

Psoriasis has a substantial emotional impact on an individual, which is not necessarily related to the extent of skin disease. One-fourth of patients with psoriasis have sexually-affected lives after the onset of psoriasis, regardless of gender. Sexual dysfunction is one of the causal factors in reducing the quality of life in patients with psoriasis, along with low self-esteem, anxiety, depression and suicidal ideation. Sexual dysfunction in psoriasis is influenced by factors such as the severity of psoriasis, psoriasis body area and associated physical and/or psychic comorbidities ${ }^{(4)}$.

According to the World Health Organization (WHO), sexuality is a basic need and an aspect of human beings that cannot be separated from others, extremely important in maintaining good mental health. The impact of psoriasis on sexual functioning is significant, because the condition causes intense interpersonal strain, hindering quality of life ${ }^{(4)}$.

The study aimed to assess female sexual dysfunction and their correlation with psoriasis severity.

\section{PATIENTS AND METHODS}

This was a case-control study that included 30 female patients with a diagnosis of psoriasis (psoriasis group), in addition to 20 female healthy volunteers of matched age and sex as a control group. All patients were selected from the Outpatient Clinic of Dermatology, Venereology and Andrology Department, Zagazig University Hospitals through the period from March 2019 to January 2020.

\section{Ethical considerations:}

An informed consent was obtained from all participants. The present study was approved by the Ethics Committee on research involving human subjects of Faculty of Medicine, Zagazig University.

Inclusion criteria: Females with age ranging between 18 to 60 years old and having active sexual life.

For psoriatic group: Clinically typical psoriatic lesions with different clinical varieties of psoriasis, and different degrees of severity of psoriasis according to Psoriasis Area and Severity Index (PASI) score.

Exclusion criteria: Age $<18$ or $>60$, receiving topical therapy for 2 weeks or systemic therapy for 1 month before being enrolled in our study, receiving hormonal therapy as oral contraceptive pills, presence of gynecological disorders potentially affecting sexual function including (vaginitis, chronic pelvic pain, malignant neoplasm, vaginismus and alteration of Pelvic anatomy), pregnancy, breast-feeding, renal, hepatic or endocrinopathic diseases, and patient 
diagnosed with primary psychiatric disorder such as (depression or anxiety).

All patients were subjected to the following:

A. Full history taking

1. Personal history: The patient's name, age, sex and marital status.

2. Present history: onset, course and duration of psoriasis.

3. Past history of medication intake: Type and duration of medication intake and dose.

4. Previous treatment of psoriasis: Systemic or topical, duration and dose.

5. Family history of Psoriasis, or other skin or systemic diseases.

6. History of associated comorbidities e.g. Diabetes, hypertension dyslipidemia, liver and renal diseases.

\section{B. Examination:}

1. Clinical assessment of cases:

a. Type of psoriasis and site of lesions were recorded.

b. Presence of arthritis, genital involvement and exposed skin areas (scalp, face, hand).

c. Grading of the disease severity according to the PASI score ${ }^{(5)}$.

d. Clinical Assessment of female sexual function by FSFI ${ }^{(6)}$.

\section{Scoring method}

The PASI combines assessments of 4 body areas: the head and neck $(\mathrm{H})$, the upper limbs (UL), the trunk (T) and the lower limbs (LL). The percentage of skin affected by psoriasis in each area is given a numerical score (A) representing the proportion involved: 1 (0-9\%), 2 (10-29\%), 3 (30$49 \%), 4(50-69 \%), 5(70-89 \%)$ and $6(90-100 \%)$ within each area (H, UL, T, LL).

The severity of 3 plaque signs - erythema (E), thickness/induration (I) and desquamation/scaling (D) - is assessed on a 5-point scale: 0 (none), 1 (mild), 2 (moderate), 3 (severe) or 4 (very severe).

The final PASI score ranges from 0 to 72 , and is calculated using the following formula: PASI $=$ $0.1(\mathrm{EH}+\mathrm{IH}+\mathrm{DH}) \mathrm{AH}+0.2(\mathrm{EUL}+\mathrm{IUL}+\mathrm{DUL}) \mathrm{AUL}$ $+0.3(\mathrm{ET}+\mathrm{IT}+\mathrm{DT}) \mathrm{AT}+0.4(\mathrm{ELL}+\mathrm{ILL}+\mathrm{DLL})$ ALL. (EH: erythema in head, EUL: erythema in upper limb , ET: erythema in trunk, IH: induration in head, IUL: indurations in upper limb, IT: induration in trunk, DH: desquamation in head, DUL: desquamation in upper limb, DT: desquamation in trunk AH: area score in head, AUL: area score in upper limb, AT: area score in trunk, ELL: erythema in lower limb, ILL: induration in lower limb DLL: desquamation in lower limb, ALL: area score in lower limb) ${ }^{(7)}$. According to PASI score, psoriatic patients were classified into mild (If PASI score < 10) moderate (If PASI score 10 - 20) or severe (If PASI score $>20)^{(\mathbf{8})}$.

2. Determining the sexual function through female sexual function index (FSFI):

FSFI, a self-reported questionnaire measured the female sexual function during the previous 4 weeks, which has been previously validated in the Arabic language ${ }^{(6)}$. The FSFI is a valid and accurate method to measure the female sexual function. This questionnaire comprises of 19 questions that evaluate six different domains of sexual function including desire, arousal, lubrication, orgasm, satisfaction and pain. The answer is rated on a 5-point Likert scale between 0 and 5. Each domain score was obtained by adding individual items of the domain and multiplying this result by the domain factor (i.e. desire, 0.6; arousal and lubrication, 0.3; orgasm, satisfaction and pain, 0.4) ${ }^{\left({ }^{(9)}\right.}$. The FSFI total score is determined by the sum of the six domains. The score varies from 2 to 36, where higher scores are associated with the lower degree of sexual dysfunction ${ }^{(9)}$. A total score of 26.5 is the cutoff point for women with sexual dysfunction ${ }^{(\mathbf{1 0})}$.

Six FSFI sexual domains have cutoffs in each of their domains. Desire has a domain value with a cutoff of 2.4. Values below 2.4 fall into the category of dysfunction, and above 2.4 falls into normal category. The other five domains, (the arousal, lubrication, orgasm, satisfaction and pain), have a cutoff value of 3.6. Values below3.6 belong to dysfunction category, while above 3.6 is considered normal ${ }^{(\mathbf{1 0})}$.

\section{Statistical Analysis}

Data collected throughout history, basic clinical examination, laboratory investigations and outcome measures were coded, entered and analyzed using Microsoft Excel software. Data were then imported into Statistical Package for the Social Sciences (SPSS version 20.0) software for analysis. According to the type of data, qualitative was represent as number and percentage and quantitative continues group was represent by mean $\pm \mathrm{SD}$.

The following tests were used to test differences for significance: Difference and association of qualitative variable by Chi square test $\left(\mathrm{X}^{2}\right)$, differences between quantitative independent groups by $t$ test or Mann Whitney and correlation by Pearson's correlation or Spearman's. P value $\leq 0.05$ for significant results \& $<0.001$ for high significant result.

\section{RESULTS}

The mean age (years) of psoriatic group was $40.53 \pm 12.18$ vs $39.4 \pm 12.33$ for control group with no significant difference between them. More than half of both groups were less than 40 years old (Table 1 ). 
Table (1): Age distribution between cases and control

\begin{tabular}{|c|c|c|c|c|c|c|}
\hline & $\begin{array}{c}\text { Psoriasis } \\
\text { group }\end{array}$ & \begin{tabular}{|c|}
$\begin{array}{c}\text { Control } \\
\text { group }\end{array}$ \\
\end{tabular} & $t / X^{2}$ & $\mathbf{P}$ \\
\hline \multicolumn{3}{|c|}{$\begin{array}{l}\text { Age (years) } \\
\text { Mean } \pm \text { SD }\end{array}$} & $\begin{array}{c}40.53 \pm \\
12.18\end{array}$ & $\begin{array}{l}39.4 \pm \\
12.33\end{array}$ & 0.321 & 0.750 \\
\hline \multirow{4}{*}{ Age } & \multirow{2}{*}{$<40$} & $\mathbf{N}$ & 16 & 11 & & \\
\hline & & $\%$ & $53.3 \%$ & $55.0 \%$ & & \\
\hline & \multirow{2}{*}{$>40$} & $\mathbf{N}$ & 14 & 9 & 0.013 & 0.908 \\
\hline & & $\%$ & $46.7 \%$ & $45.0 \%$ & & \\
\hline \multirow{2}{*}{\multicolumn{2}{|c|}{ Total }} & $\mathbf{N}$ & 30 & 20 & & \\
\hline & & $\%$ & $100.0 \%$ & $100.0 \%$ & & \\
\hline
\end{tabular}

$\mathrm{P}$ value $>0.05$ non-significant

The mean FSFI was significantly lower in psoriatic group $(20.42 \pm 4.21)$ than in control group (23.76 \pm $4.85)$, $(\mathrm{p}$ value $=0.033)$. Regarding sub-items of FSFI ; the mean of all sub-items of FSFI were lower in psoriatic group than in control group with no statistically significance except for orgasm the mean was significantly lower in psoriasis group $(3.46 \pm 1.19)$ than in control group $(4.263 \pm 1.0)$ ( $\mathrm{p}$ value $=0.042)$. The mean of pain was higher in psoriatic group (3.77 \pm 0.37) than in control group $(3.69 \pm 0.26)$ with no statistically significant difference between both groups (Table 2).

Table (2): FSFI total and sub-items level distribution between cases and controls

\begin{tabular}{||l|c|c|c|c|}
\hline & $\begin{array}{c}\text { Psoriasi } \\
\text { s group } \\
\text { Mean } \pm \\
\text { SD }\end{array}$ & $\begin{array}{c}\text { Control } \\
\text { group } \\
\text { Mean } \pm \\
\text { SD }\end{array}$ & t & P \\
\hline \hline FSFI & $\begin{array}{c}20.42 \pm \\
4.21\end{array}$ & $\begin{array}{c}23.76 \pm \\
4.85\end{array}$ & -2.195 & $0.033^{*}$ \\
\hline Desire & $\begin{array}{c}3.15 \pm \\
0.84\end{array}$ & $\begin{array}{c}3.57 \pm \\
0.93\end{array}$ & -1.643 & 0.107 \\
\hline Arousal & $\begin{array}{c}3.08 \pm \\
0.97\end{array}$ & $\begin{array}{c}3.59 \pm \\
1.01\end{array}$ & -1.792 & 0.079 \\
\hline Lubrication & $\begin{array}{c}3.83 \pm \\
0.72\end{array}$ & $\begin{array}{c}4.33 \pm \\
1.19\end{array}$ & -1.841 & 0.072 \\
\hline Orgasm & $\begin{array}{c}3.46 \pm \\
1.19\end{array}$ & $\begin{array}{c}4.263 \pm \\
1.0\end{array}$ & -2.140 & $0.042^{*}$ \\
\hline Satisfaction & $\begin{array}{c}3.82 \pm \\
1.27\end{array}$ & $\begin{array}{c}4.2 \pm \\
1.31\end{array}$ & -0.847 & 0.401 \\
\hline Pain & $\begin{array}{c}3.77 \pm \\
0.37\end{array}$ & $\begin{array}{c}3.69 \pm \\
0.26\end{array}$ & 0.808 & 0.423 \\
\hline
\end{tabular}

$* \mathrm{P}$ value $\leq 0.05$ significant

There was a significant negative correlation between age and FSFI among control group ( $\mathrm{p}$ value $=$ $0.002),(r=-.650-)$. However, there was no significant correlation between FSFI and age among psoriatic patients $(\mathrm{p}$ value $=0.188)($ Table 3$)$.
Table (3): Correlation between FSFI and age in both groups

\begin{tabular}{|c|c|c|c|}
\hline \multicolumn{2}{|c}{ Group } & FSFI \\
\hline \hline \multirow{2}{*}{ Psoriasis group } & \multirow{2}{*}{$\begin{array}{c}\text { Age } \\
\text { (years) }\end{array}$} & $\mathbf{r}$ & $-.247-$ \\
\cline { 3 - 4 } & $\mathbf{P}$ & .188 \\
\hline \multirow{2}{*}{ Control group } & $\begin{array}{c}\text { Age } \\
\text { (years) }\end{array}$ & $\mathbf{r}$ & $-.650-^{* *}$ \\
\cline { 3 - 4 } & & $\mathbf{P}$ & $.002^{*}$ \\
\hline
\end{tabular}

$* \mathrm{P}$ value $\leq 0.05$ significant

FSFI score was significantly negatively correlated with PASI score ( $\mathrm{p}$ value $=0.004),(\mathrm{r}=-.508$-). While there was no significant correlation between FSFI and the duration of psoriasis ( $\mathrm{p}$ value $=0.515)($ Table 4$)$.

Table (4): Correlation of FSFI with PASI and duration of psoriasis

\begin{tabular}{|c|c|c|c|}
\hline \multicolumn{2}{|c|}{ Group } & FSFI \\
\hline \hline \multirow{2}{*}{$\begin{array}{c}\text { FSFI in Psoriasis } \\
\text { group }\end{array}$} & \multirow{2}{*}{$\begin{array}{c}\text { Duration } \\
\text { disease }\end{array}$} & $\mathbf{r}$ & $-.124-$ \\
\cline { 3 - 4 } & \multirow{2}{*}{ PASI } & $\mathbf{P}$ & .515 \\
\cline { 3 - 4 } & & $\mathbf{P}$ & $.008^{* *}$ \\
\hline
\end{tabular}

$* \mathrm{P}$ value $\leq 0.05$ significant.

77\% of patients with mild PASI presented with sexual dysfunction while all patients with moderate to severe PASI had sexual dysfunction (Table 5).

Table (5): Percentage of sexual dysfunction in different PASI score

\begin{tabular}{|c|c|c|c|c|}
\hline PASI & $\begin{array}{c}\text { N. without } \\
\text { SD }\end{array}$ & $\%$ & $\begin{array}{c}\text { N. with } \\
\text { SD }\end{array}$ & $\%$ \\
\hline \hline Mild & 3 & $23 \%$ & 10 & $77 \%$ \\
\hline Moderate & - & 0 & 6 & $100 \%$ \\
\hline Sever & - & 0 & 11 & $100 \%$ \\
\hline
\end{tabular}

$\mathrm{N}=$ number of patients $\quad \mathrm{SD}=$ sexual dysfunction

\section{DISCUSSION}

In the present study, the mean of all six FSFI domains were lower in psoriatic group than in control group except pain was increased but with no statistically significant difference between both groups. This finding comes in agreement with Ermertcan (11), who reported that the FSFI total score was found to be significantly decreased in the psoriasis group compared to healthy controls and all FSFI domain scores were found to be significantly decreased in psoriasis compared to control group except lubrication and pain.

In our study, orgasm was found to be significantly decreased in female patients with psoriasis than in control group. This comes in agreement with Mercan et al. ${ }^{(\mathbf{1 2})}$, who stated that orgasmic problems were more pronounced affected than desire in female psoriatic patients. They concluded that may be there are some other reasons than depression for sexual 
dysfunction in psoriatic patients. In contrast, Abul Maaty et al. ${ }^{(13)}$ stated that although sexual desire is decreased in psoriatic patients, pain and orgasm were less affected with an insignificant decrease.

Maseroli et al. (14) suggested that diabetes mellitus (DM) had been associated with impairment of orgasmic function. Also Seftel ${ }^{(15)}$ supposed that DM may lead to decrease in arousal and lubrication as a secondary to decreased vascular genital flow in women with DM.

Results of the present study showed that there was a significant negative correlation between FSFI and psoriasis severity (PASI). These results are in agreement with Niemeier et al. ${ }^{(16)}$ and Abul Maaty et al. ${ }^{(13)}$ who revealed a significant negative correlation between PASI scores and FSFI. In contrast, Ermertcan (11) reported absence of significant correlation between FSFI scores and psoriasis severity (PASI).

In addition, our study reported a significant negative correlation between age and FSFI among control group. In contrast to psoriasis group, there was no correlation between FSFI and either age or duration of disease.

The effect of aging on sexual function in women has also been reviewed by Hayes and Lorraine ${ }^{(17)}$, they reported a clear decline in sexual function in the menopausal years, but within the reproductive years, the percentage of women reporting difficulties with sexual interest and arousal appears to remain static. This result disagree with Abul Maaty et al. ${ }^{(13)}$ who reported a significant effect of age of the patients with psoriasis and the duration of the disease on FSFI score.

\section{CONCLUSION}

The mean of all six FSFI domains were lower in psoriatic group than in control group except for pain that was increased but with no statistically significant difference between both groups. Orgasm was found to be significantly decreased in female patients with psoriasis than in control group. There was a significant negative correlation between female sexual function index (FSFI) and psoriasis severity (PASI). There was a significant negative correlation between age and FSFI among control group. In contrast to psoriasis group, there was no correlation between FSFI and either age or duration of disease.

\section{REFERENCES}

1. Michalek I, Loring B, John S (2017): A Systematic Review of Worldwide Epidemiology of Psoriasis." Journal of the European Academy of Dermatology and Venereology, 31 (2): 205-12.

2. Gaytri K, Vikram K, Karaninder S et al. (2017): Serum Prolactin Levels in Patients with Psoriasis: Results of a Pilot Study. The Indian Journal of Medical Research, 145 (2): 250-252.
3. Naoko K, Shinichi W (2005): Regulatory Roles of Sex Hormones in Cutaneous Biology and Immunology." Journal of Dermatological Science, 38 (1): 1-7.

4. Shu K, Henrique da Mota L (2012): Sexual Dysfunction in Patients with Psoriasis and Psoriatic Arthritis-a Systematic Review. Revista Brasileira de Reumatologia, 52 (6): 943-948.

5. Jochen S, Wozel G (2005): The Psoriasis Area and Severity Index Is the Adequate Criterion to Define Severity in Chronic Plaque-Type Psoriasis. Dermatology, 210 (3): 194-199.

6. Tarek H, Samah A, Hanan S et al. (2011): Arabic Translation of Female Sexual Function Index and Validation in an Egyptian Population. The Journal of Sexual Medicine, 8 (12): 3370-3378.

7. Berth- Jones J, Grotzinger K, Rainville C et al. (2006): A Study Examining Inter- and Intrarater Reliability of Three Scales for Measuring Severity of Psoriasis: Psoriasis Area and Severity Index, Physician's Global Assessment and Lattice System Physician's Global Assessment. British Journal of Dermatology, 155 (4): 707-713.

8. Anna B, Myśliwiec H, Szterling-Jaworowska M et al. (2018): Serum YKL-40 as a Potential Biomarker of Inflammation in Psoriasis. Journal of Dermatological Treatment, 29 (1): 19-23.

9. Heiman J , Leiblum S, Meston C et al. (2000): The Female Sexual Function Index (FSFI): A Multidimensional Self-Report Instrument for the Assessment of Female Sexual Function. Journal of Sex \& Marital Therapy, 26 (2): 191-208.

10. Bang- Ping J, Su C, Yu C et al. (2009): Risk Factors for Individual Domains of Female Sexual Function. The Journal of Sexual Medicine, 6 (12): 3364-3375.

11. Ermertcan A (2009): Sexual Dysfunction in Dermatological Diseases. Journal of the European Academy of Dermatology and Venereology, 23 (9): 9991007.

12. Mercan S, Altunay I, Akpİnar B et al. (2008): Sexual Dysfunctions in Patients with Neurodermatitis and Psoriasis. Journal of Sex \& Marital Therapy, 34 (2): 160168.

13. Abul Maaty H, Gomaa H, Mohammed G et al. (2013): Assessment of Female Sexual Function in Patients with Psoriasis. The Journal of Sexual Medicine, 10 (6): 15451548.

14. Maseroli E, Irene S, Linda V (2018): Cardiometabolic Risk and Female Sexuality-Part I. Risk Factors and Potential Pathophysiological Underpinnings for Female Vasculogenic Sexual Dysfunction Syndromes. Sexual Medicine Reviews, 6 (4): 508-524.

15. Seftel D (2017): Re: Cardiometabolic Risk and Female Sexuality: Focus on Clitoral Vascular Resistance. The Journal of Urology, 197 (4): 1133-1134.

16. Niemeier V, Thomas W, Gieler U (1997): Skin Disease and Sexuality. An Empirical Study of Sex Behavior or Patients with Psoriasis Vulgaris and Neurodermatitis in Comparison with Skin-Healthy Probands. Der Hautarzt; Zeitschrift Fur Dermatologie, Venerologie, Und Verwandte Gebiete, 48 (9): 629-633.

17. Hayes R, Lorraine D (2005): The Impact of Aging on Sexual Function and Sexual Dysfunction in Women: A Review of Population- based Studies. The Journal of Sexual Medicine, 2 (3): 317-330. 